\title{
TUMOR TARGETING WITH INTEGRIN LIGAND - DRUG CONJUGATES ${ }^{1}$
}

\author{
CESARE GENNARI (*) \\ Nota presentata dal m.e. S. Maiorana \\ (Adunanza del 18 gennaio 2018)
}

Drug targeting to tumors is a field of growing interest in modern oncology. Indeed, the main limitation of traditional chemotherapy is the unselective release of aggressive cytotoxic agents. As a consequence of this lack of selectivity, high drug dosages are required, causing severe side effects and thus affecting the overall efficiency of the therapy. A successful drug targeting approach is represented by the conjugation of extremely potent anticancer drugs to monoclonal antibodies (mAbs): by binding to tumor-specific antigens, the $\mathrm{mAb}$ enables the selective recognition of cancer cells. The drug load is then released in the intracellular environment upon receptor-mediated endocytosis. Four antibody-drug conjugates (ADCs) have recently reached the market: (i) ado-trastuzumab emtansine $\left(\mathrm{Kadcyla}^{\circledR}\right)$ is indicated for the treatment of patients with HER2-positive, metastatic breast cancer; (ii) brentuximab vedotin (Adcetris ${ }^{\circledR}$ ) is indicated for the treatment of Hodgkin lymphoma and anaplastic large cell lymphoma; (iii) inotuzumab ozogamicin (Besponsa $\left.{ }^{\circledR}\right)$ is indicated for the treatment of adults with relapsed or refractory B-cell precursor acute lymphoblastic leukemia (ALL); (iv) gemtuzumab ozogamicin (Mylotarg ${ }^{\circledR}$ ) is indicated for adults with newly

(*) Università degli Studi di Milano, Dipartimento di Chimica, Milano, Italy.

E-mail: cesare.gennari@unimi.it

1 Sintesi dell'intervento. 
diagnosed CD33-positive acute myeloid leukemia (AML), and adults and children 2 years and older with relapsed or refractory CD33-positive AML. Although the ADC technology has been catching the interest of the world's biggest pharmaceutical companies, this approach presents several drawbacks: besides the high manufacturing costs, the administration of antibodies as drug carriers is often limited by pharmacokinetic issues (e.g., difficult extravasation, low tissue diffusion, low accumulation inside the tumor mass) and by possible immune system-induced alterations of drug efficiency.

To trespass these limitations, small molecule-drug conjugates (SMDCs) have been proposed as a possible alternative to ADCs. Here, tumor targeting is effected by a small molecule (e.g., an oligopeptide, a peptidomimetic or a vitamin), which is capable of selectively binding to tumor-overexpressed antigens. The main advantages of this approach compared to ADCs are better pharmacokinetics (due to the smaller size of the targeting agent) and an easier and more economical preparation.

In the field of SMDCs, integrin $\alpha_{\mathrm{v}} \beta_{3}$ represents a very interesting target to be exploited for the selective delivery of anticancer agents within the tumor site.[1] Integrins are a large family of heterodimeric transmembrane glycoprotein receptors, composed by two non-covalentlyassociated subunits ( $\alpha$ and $\beta$ ). The expression of integrin $\alpha_{v} \beta_{3}$ is increased in a variety of human cancer types (e.g. breast cancer, glioblastoma, pancreatic tumor, prostate carcinoma) with respect to healthy tissues. The increased expression of $\alpha_{v} \beta_{3}$ integrin in tumor cells is associated with different pathological features: angiogenesis, tumor growth, apoptosis resistance, and metastasis. Integrin $\alpha_{v} \beta_{3}$ recognizes endogenous ligands by the tripeptide arginine-glycine-aspartate (RGD) and also by the related sequence isoaspartate-glycine-arginine (isoDGR).

We have investigated the synthesis and biological properties of a new class of cyclic peptidomimetics containing a bifunctional diketopiperazine (DKP) scaffold and the tripeptide sequence Arg-Gly-Asp (RGD) [2,3] or isoAsp-Gly-Arg (isoDGR) [4] as potent integrin ligands. Competitive binding assays for the displacement of biotinylated vitronectin bound to purified $\alpha_{\mathrm{V}} \beta_{3}$ integrin displayed excellent $\mathrm{IC}_{50} \mathrm{val}$ ues, in the low nanomolar range [5]. The interaction of cyclo[DKPRGD] ligands with intact cancer cells was investigated by NMR and computational studies, allowing the determination of the binding epitope and the bioactive conformation of the ligands [6]. Cyclo[DKPRGD] and cyclo[DKP-isoDGR] ligands proved to be potent angiogen- 
esis inhibitors and genuine integrin antagonists [7]. Since $\alpha_{\mathrm{V}}$ integrins are overexpressed on the surface of cancer cells, integrin ligandPaclitaxel conjugates were synthesized with the aim of using the tumorhoming cyclo[DKP-RGD] or cyclo[DKP-isoDGR] peptidomimetics for site-directed delivery of the cytotoxic drug $[8,9,10]$. Recently, multivalency was found to increase the binding strength of $c y c l o$ [DKP-RGD] peptidomimetic-Paclitaxel conjugates to integrin $\alpha_{\mathrm{v}} \beta_{3}$ [11].

Integrin ligand-Paclitaxel conjugates were tested with isogenic cancer cell lines having different levels of integrin expression $\left(\alpha_{v} \beta_{3}+\right.$ and $\left.\alpha_{\mathrm{V}} \beta_{3^{-}}\right)$and displayed a remarkable Targeting Index $\left[\mathrm{IC}_{50}\right.$ (cancer cells $\left.\alpha_{v} \beta_{3^{-}}\right) / \mathrm{IC}_{50}\left(\right.$ cancer cells $\left.\left.\alpha_{\mathrm{V}} \beta_{3}+\right)\right]=10^{1}$. However, this value is much lower than those exhibited by ADCs (T.I. ca. 103). Therefore, despite the significant progresses that have been realized in recent years, integrin targeting SMDCs require additional fine tuning of the linker in order to improve the potency and the selectivity of the conjugates (Fig. 1).

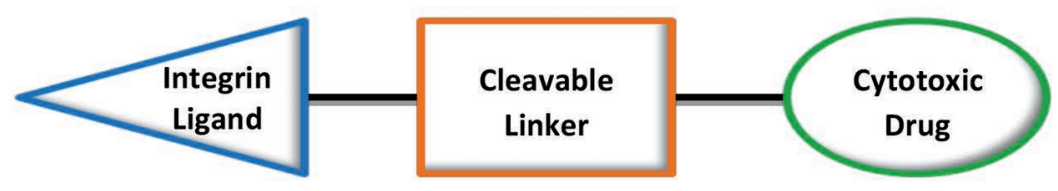

Fig. 1.

\section{ACKNOWLEDGEMENTS}

I gratefully acknowledge MIUR (PRIN project 20157WW5EH "Tumor-targeting peptidomimetics: synthesis and bio-medical applications") and the European Commission (Marie Skłodowska-Curie ITN MAGICBULLET 642004 "Peptide-Drug Conjugates for Targeted Delivery in Tumor Therapy") for financial support.

\section{REFERENCES}

1. Dal Corso, A., Pignataro, L., Belvisi, L., Gennari, C. Current Topics in Medicinal Chemistry 2016, 16, 314-329.

2. Ressurreição, A. S. M., Vidu, A., Civera, M., Belvisi, L., Potenza, D., Manzoni, L., Ongeri, S., Gennari, C., Piarulli, U. Chem. Eur. J. 2009, 15, 12184-12188.

3. Marchini, M., Mingozzi, M., Colombo, R., Guzzetti, I., Belvisi, L., Vasile, F., 
Potenza, D., Piarulli, U., Arosio, D., Gennari C. Chem. Eur. J. 2012, 18, 6195 6207.

4. Mingozzi, M., Dal Corso, A., Marchini, M., Guzzetti, I., Civera, M., Piarulli, U., Arosio, D., Belvisi, L., Potenza, D., Pignataro, L., Gennari C. Chem. Eur. J. 2013, 19, 3563-3567.

5. For similar studies on integrin $\alpha_{\mathrm{v}} \beta_{6}$, see: Civera, M., Arosio, D., Bonato, F., Manzoni, L., Pignataro, L., Zanella, S., Gennari, C., Piarulli, U., Belvisi, L. Cancers 2017, 9, 128.

6. (a) Guzzetti, I., Civera, M., Vasile, F., Araldi, E. M., Belvisi, L., Gennari C., Potenza, D., Fanelli, R., Piarulli, U. Org. Biomol. Chem. 2013, 11, 3886-3893. (b) Guzzetti, I., Civera, M., Vasile, F., Arosio, D., Tringali, C., Piarulli, U., Gennari, C., Pignataro, L., Belvisi, L., Potenza, D. ChemistryOpen 2017, 6, 128-136.

7. Panzeri, S., Zanella, S., Arosio, D., Vahdati, L., Dal Corso, A., Pignataro, L., Paolillo, M., Schinelli, S., Belvisi, L., Gennari, C., Piarulli, U. Chem. Eur. J. 2015, 21, 6265-6271.

8. Colombo, R., Mingozzi, M., Belvisi, L., Arosio, D., Piarulli, U., Carenini, N., Perego, P., Zaffaroni, N., De Cesare, M., Castiglioni, V., Scanziani, E., Gennari C. J. Med. Chem. 2012, 55, 10460-10474.

9. Dal Corso, A., Caruso, M., Belvisi, L., Arosio, D., Piarulli, U., Albanese, C., Gasparri, F., Marsiglio, A., Sola, F., Troiani, S., Valsasina, B., Pignataro, L., Donati D., Gennari, C. Chem. Eur. J. 2015, 21, 6921 - 6929.

10. Zanella, S., Angerani, S., Pina, A., López Rivas, P., Giannini, C., Panzeri, S., Arosio, D., Caruso, M., Gasparri, F., Fraietta, I., Albanese, C., Marsiglio, A., Pignataro, L., Belvisi, L., Piarulli, U., Gennari, C. Chem. Eur. J. 2017, 23, 7910-7914.

11. Raposo Moreira Dias, A., Pina, A., Dal Corso, A., Arosio, D., Belvisi, L., Pignataro, L., Caruso, M., Gennari, C. Chem. Eur. J. 2017, 23, 14410-14415. 